\title{
Isolation of marine yeasts from coastal waters of northeastern Taiwan
}

\author{
Yi-Sheng Chen ${ }^{1, *}$, Fujitoshi Yanagida ${ }^{2}$, Liang-Yu Chen ${ }^{1}$ \\ ${ }^{1}$ Department of Biotechnology, Ming Chuan University, No. 5 De-Ming Rd., Gui-Shan, Taoyuan 333, Taiwan \\ ${ }^{2}$ The Institute of Enology and Viticulture, Yamanashi University, 1-13-1 Kitashin, Kofu, Yamanashi 400-0005, Japan
}

\begin{abstract}
Twelve seawater samples were collected from the coastal marine waters of northeastern Taiwan, and 109 yeast cultures were isolated from the samples. Isolates were first classified by phenotype and then into 9 groups according to restriction fragment length polymorphism (RFLP) analysis and the sequencing of 5.8S-ITS ribosomal DNA. The results showed that Candida tropicalis was the most frequently recovered yeast found in the coastal waters of northeastern Taiwan. Other species found in this study included C. glabrata, Saccharomyces yakushimaensis, Kazachstania jiainicus, Kodamaea ohmeri, Pichia anomala, Issatchenkia orientalis, and Hanseniaspora uvarum. The biodiversity of yeast species was determined from the south to north of the northeastern coastal waters.
\end{abstract}

KEY WORDS: Marine yeasts · Candida tropicalis · Taiwan

\section{INTRODUCTION}

Yeasts are primarily used by the food industry in the production of alcohol and carbon dioxide, which are important to the brewing, alcohol distillation, and baking industries (Yanagida et al. 2002). Yeasts can also be applied to various other fields, such as in the production of biofuel, biocontrol of fungi in agriculture, and other applications in biotechnology (Passoth \& Schnürer 2003, Hill et al. 2006, Matsushika et al. 2008).

Yeasts are widely distributed in the terrestrial environment, including plants and soil, as well as in wine and various foods (Nisiotou \& Gibson 2005, Bhadra et al. 2007, Nyanga et al. 2007, Lee et al. 2008, Liu et al. 2008, Rao et al. 2008). However, yeasts with different metabolic attributes have been reported to occur in aquatic environments, such as oceans and seas, estuaries, lakes, and rivers (Kutty \& Philip 2008).

Marine yeasts are ubiquitous in the marine environment. They are frequently found in the digestive tract of marine organisms and in seawater and beach sand (van Uden \& Branco 1963, Taysi \& van Uden 1964, Kawakita \& van Uden 1965, Fell 1967, Vogel et al. 2007, Kutty \& Philip 2008). It is therefore considered that the factors affecting the distribution of marine yeasts include currents, migration of marine organisms, and contamination from terrigenous sources (van Uden \& Branco 1963, Fell 1967, Vogel et al. 2007, Kutty \& Philip 2008).

Indigenous marine yeasts need to grow on or in a marine substrate. However, salinity tolerance does not distinguish marine species from terrestrial species, because some terrestrial species can grow in sodium chloride concentrations exceeding those normally present in the sea (Yamagata \& Fujita 1970, Kutty \& Philip 2008). Previous studies reported that marine yeasts do not belong to a specific genus or group, but are represented by a wide variety of well-known genera, such as Candida, Cryptococcus, Debaryomyces, Pichia, Hansenula, Rhodotorula, Saccharomyces, Trichosporon, and Torulopsis (Kutty \& Philip 2008).

Recently, various molecular techniques have been applied to discriminate or identify yeast species. Restriction fragment length polymorphism (RFLP) analysis is a simple method of comparing the molecular profiles of DNA sequences that provides information on composition without analyzing the DNA sequences. RFLP and sequence analysis of the 5.8S rDNA gene and its flanking internal transcribed spacer regions, collectively called 5.8S-ITS, has been proposed for yeast 
identification purposes due to its high discriminative capacity, relative ease of manipulation, and high reproducibility (Nisiotou \& Gibson 2005). Strains isolated in this study were therefore classified and identified using this method.

The distribution of marine yeasts along the coastal areas of northeastern Taiwan have not yet been studied. The purpose of this study was therefore to identify and enumerate the yeast species along the coastal areas of northeastern Taiwan. Based on our results, a hypothetical pathway of microbial spatial transportation is presented, and further information is provided to gain insight into the distribution of yeasts in this area.

\section{MATERIALS AND METHODS}

Sampling. Seawater samples were collected from 12 stations, from south to north (Stns 1 to 12), each 8 to $15 \mathrm{~km}$ apart, located along $122 \mathrm{~km}$ of coastline in northeastern Taiwan (Fig. 1). On 7 January 2008, a 21 seawater sample (from 10 to $15 \mathrm{~cm}$ depth) was collected at each station by walking along the shoreline. Each sample was collected in a sterilized bottle, which was rinsed twice with local seawater before use. Samples were analyzed within $5 \mathrm{~h}$ of acquisition at these stations. In addition to isolating yeasts, the salt concentration and $\mathrm{pH}$ of the seawater were measured. To measure the salt concentration, the seawater was placed onto the sensor of a model SK-5S salt meter (Sato Keiryoki). The $\mathrm{pH}$ was measured by placing seawater directly onto the sensor of a model B-112 compact $\mathrm{pH}$ meter (Horiba).

Isolation procedure. Isolation was performed using the methods described by Kodama (1999). Seawater samples were filtered with sterilized $0.45 \mu \mathrm{m}$ mixed cellulose ester membrane filters (ADVANTEC). After filtration, the membrane filters were laid on isolation medium (IM) plates (Table 1) and incubated at $25^{\circ} \mathrm{C}$ for $10 \mathrm{~d}$. Yeast colonies were selected from IM plates and purified by replating on IM agar plates. Colonies were reselected and initially stained with methylene blue to check their shape. Only cultures with a single shape were selected. The selected strains were stored at $-80^{\circ} \mathrm{C}$ in YM-DMSO medium (Table 1).

Classification and identification. Yeast cells were grown aerobically in YM medium (Table 1) at $25^{\circ} \mathrm{C}$. Total genomic DNA was extracted and purified from $5 \mathrm{ml}$ cultures using a DNA/RNA extraction kit (Viogene). Polymerase chain reaction (PCR) was carried out using a Takara Ex Taq gene amplification

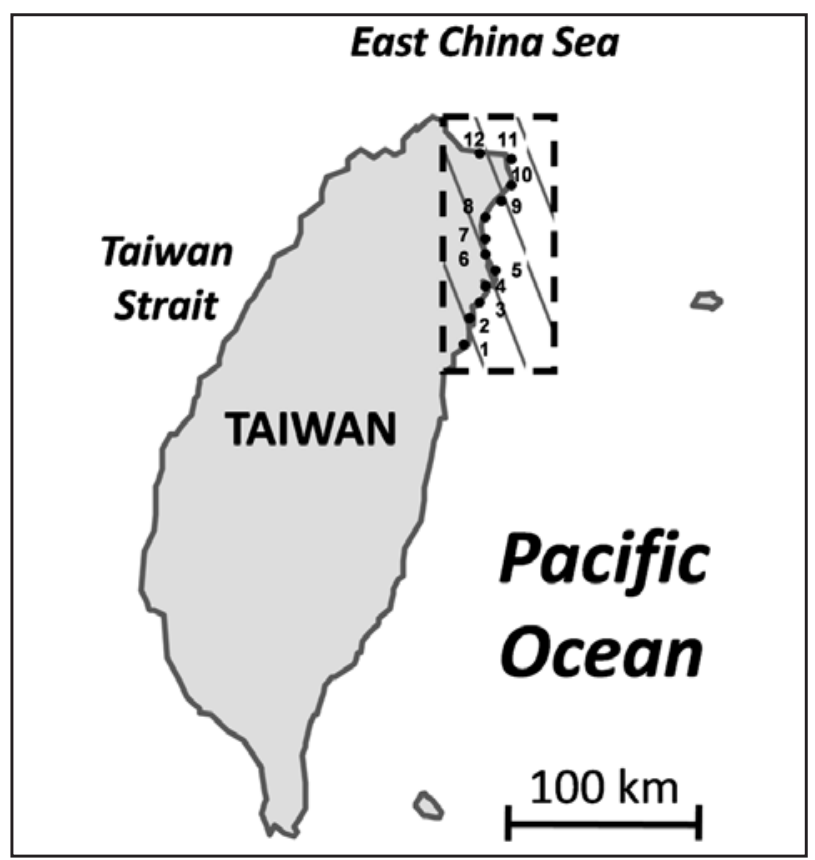

Fig. 1. Sampling area (slanted lines) with locations of sampling Stations 1-12

PCR kit and performed on a Gene Amp PCR System 9700 (PerkinElmer) following the methods described by Nisiotou \& Gibson (2005). The 5.8S-ITS rDNA region was amplified using the primers ITS1 (5'-TCC GTA GGT GAA CCT GCG G-3') and ITS4 (5'-TCC TCC GCT TAT TGA TAT GC-3') (Nisiotou \& Gibson 2005). RFLP analysis of 5.8S-ITS rDNA was carried out with the methods described by Osorio-Cadavid et al. (2008). In this study, 2 restriction enzymes, HinfI (G/ANTC) and HaeIII (GG/CC) (Osorio-Cadavid et al. 2008), were used for grouping.

For sequence analysis of 5.8S-ITS rDNA, the PCR products were purified with a Clean/Gel Extraction Kit (BioKit) and then directly sequenced using the ABI 3730 DNA Analyzer (Applied Biosystems). Sequence homologies were examined by comparing the obtained sequences to those in the DNA Data Bank of Japan (DDBJ) (www.ddbj.nig.ac.jp/) using BLAST.

Table 1. Media used

\begin{tabular}{|lcllll|}
\hline \multicolumn{2}{c}{ Isolation medium } & \multicolumn{2}{c|}{ YM-DMSO medium } & \multicolumn{2}{c|}{ YM medium } \\
\hline Sucrose & $20 \%$ & Dimethyl sulfoxide & $10 \%$ & Polypeptone & $0.5 \%$ \\
Polypeptone & $3 \%$ & Polypeptone & $0.5 \%$ & Yeast extract & $0.3 \%$ \\
Yeast extract & $3 \%$ & Yeast extract & $0.3 \%$ & Malt extract & $0.3 \%$ \\
Chloramphenicol & $100 \mathrm{ppm}$ & Malt extract & $0.3 \%$ & D-glucose & $1 \%$ \\
Agar & $1.5 \%$ & Deionized water & & Deionized water \\
Filtered seawater & & & & & \\
pH & 5.6 & & & & \\
\hline
\end{tabular}




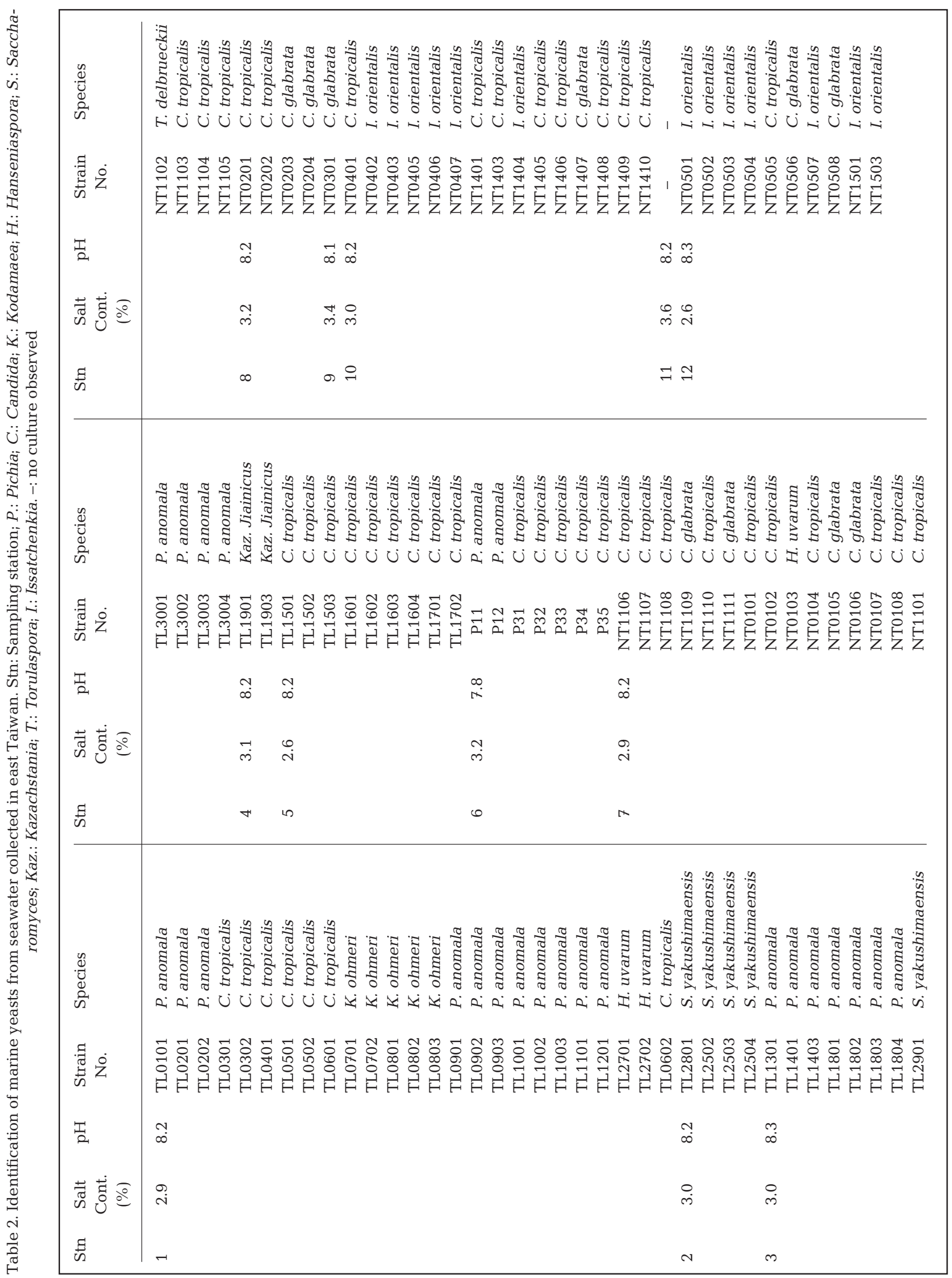




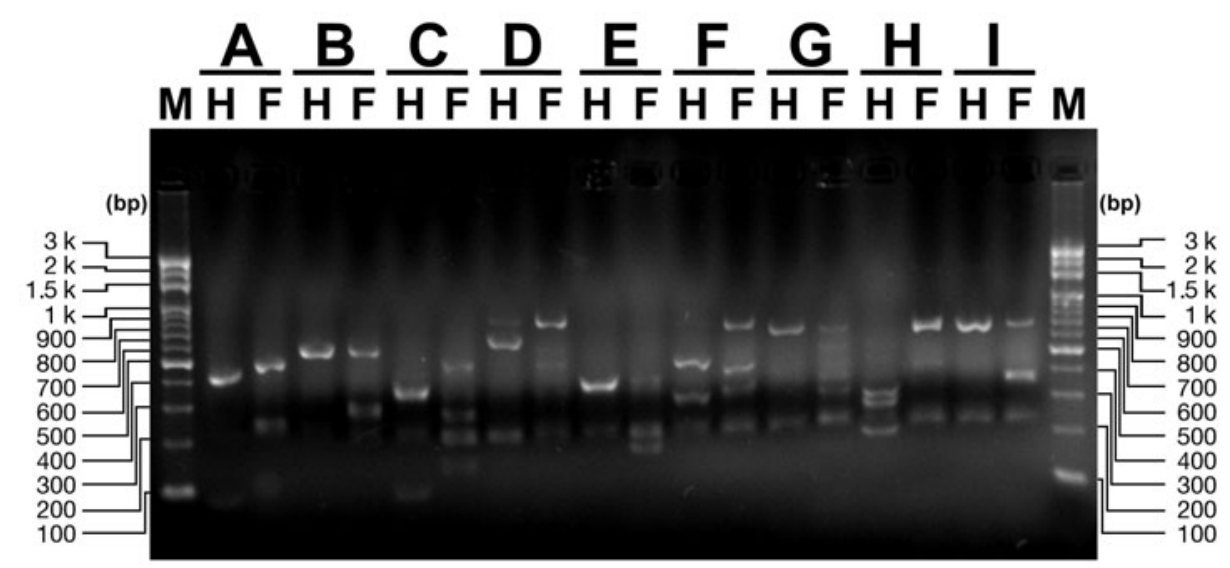

Fig. 2. 5.8S-ITS rDNA RFLP patterns of HaeIII and HinfI digests from Groups A to I. Lane M, size marker; H, HaeIII-digested patterns; F, HinfI-digested patterns

The evolutionary distance (Knuc value) and similarity values of representative strains of each group were generated using the software CLUSTAL W (http:// clustalw.ddbj.nig.ac.jp/top-j.html), and a phylogenetic tree was constructed by the neighbor-joining method with the TreeView program (v.1.66).

\section{RESULTS}

Analyses of seawater samples revealed salt concentrations from 2.5 to $3.6 \%$ and $\mathrm{pH}$ values from 8.1 to 8.3 (Table 2). The high salinity and moderately alkaline conditions indicated that the collected waters rarely mixed with riverine water.

In total, 109 cultures were isolated from the seawater samples. The number of isolates from each site is shown in Table 2. The 109 isolates were classified into 9 groups (A to I) based on cell morphology, size of the 5.8S-ITS PCR products, and the results of 5.8S-ITS rDNA RFLP analysis (Fig. 2, Table 3).

To identify the isolates, representative strains were randomly selected from each group, and 5.8S-ITS

Table 3. Classification of 109 marine yeasts found in coastal waters of northeastern Taiwan

\begin{tabular}{|llc|}
\hline Group & Species & Number \\
\hline A & Candida tropicalis & 45 \\
B & Pichia anomala & 25 \\
C & Issatchenkia orientalis & 13 \\
D & C. glabrata & 10 \\
E & Saccharomyces yakushimaensis & 5 \\
F & Kodamaea ohmeri & 5 \\
G & Hanseniaspora uvarum & 3 \\
H & Kazachstania jiainicus & 2 \\
I & Torulaspora delbrueckii & 1 \\
& Total & 109 \\
\hline
\end{tabular}

rDNA sequencing analysis was carried out. The results identified Group A isolates as Candida tropicalis, Group B as Pichia anomala, Group C as Issatchenkia orientalis, Group D as C. glabrata, Group E as Kodamaea ohmeri, Group F as Saccharomyces yakushimaensis, Group G as Hanseniaspora uvarum, Group H as Kazachstania jiainicus, and Group I as Torulaspora delbrueckii (Table 3). The sequences determined in this study have been deposited in the DDBJ database under accession numbers AB467289 to AB467306, and AB469378 to AB469381. The evolutionary distance of marine yeasts was analyzed phylogenetically, as shown in Fig. 3.

Yeast cultures were isolated from the seawater samples of all 12 sampling stations, except for Stn 11, with differences in abundance and diversity evident among the stations (Table 2). For samples at Stns 1, 7, and 10, a comparatively greater number of yeast colonies was observed and isolated after incubation (Table 2).

The most frequently recovered species, Candida tropicalis and C. glabrata, were found in 7 and 5 of the 12 stations, respectively. Saccharomyces yakushimaensis was only found at Stns 3 and 4, while Issatchenkia orientalis was only found at Stns 10 and 12 . Pichia anomala was not found at the northern sampling stations (7 to 12). Species such as Torulaspora delbrueckii and Kazachstania jiainicus were only observed at specific stations (Table 2).

\section{DISCUSSION}

Relatively few studies have investigated marine yeasts, and this group of Mycota is still poorly understood (Kutty \& Philip 2008). To the best of our knowledge, this is the first report on the distribution of marine yeasts in waters off the coast of northeastern Taiwan. As shown in Table 2, the number of yeast cul- 


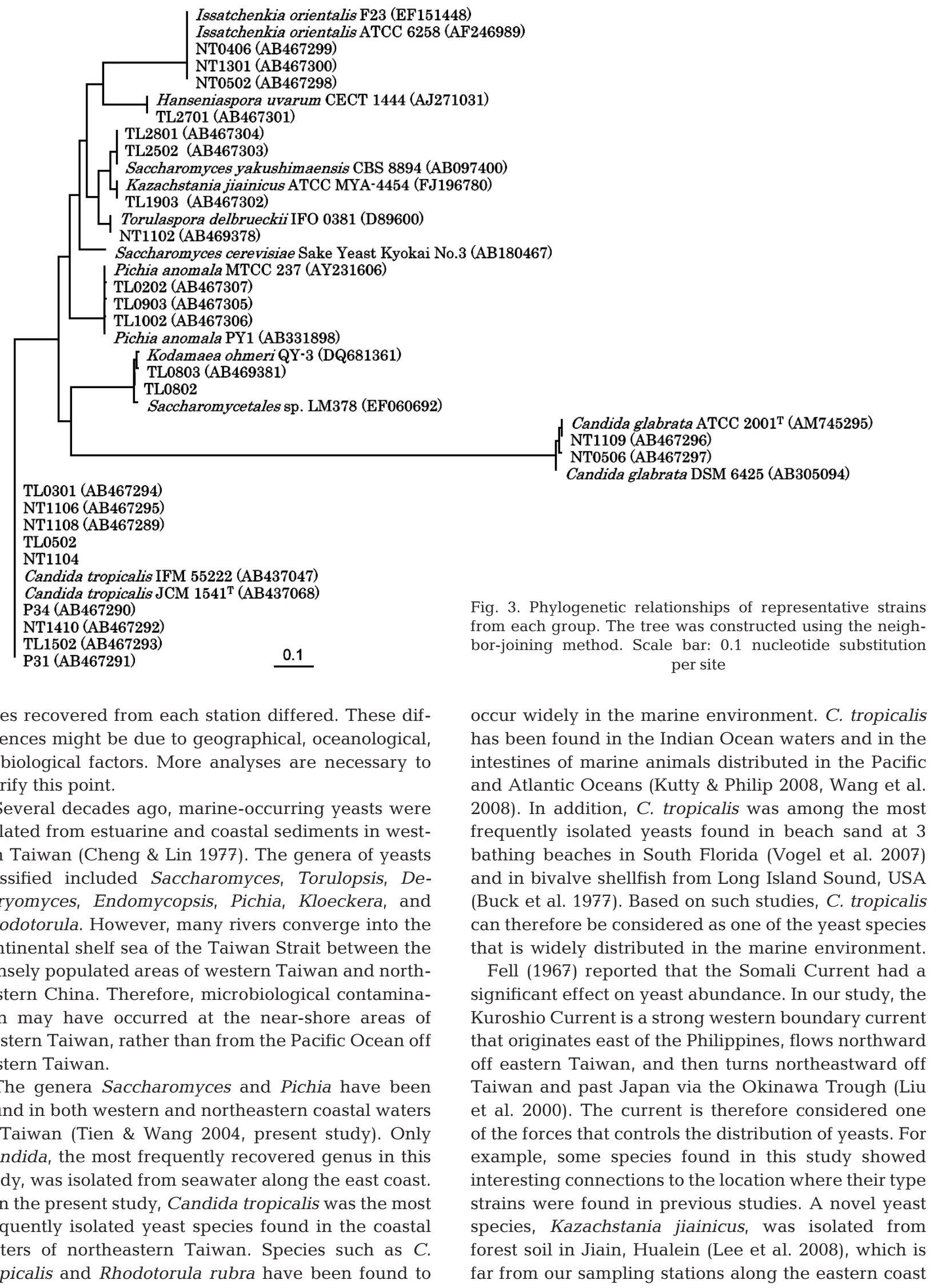


of Taiwan. Saccharomyces yakushimaensis is another interesting case; it was initially isolated from soil on Yaku Island off southern Kyushu in Japan (Mikata et al. 2001). The Kuroshio Current flows northward off the east coast of Taiwan and reaches Yaku Island 1100 $\mathrm{km}$ away (Noda et al. 1998, Liu et al. 2000). Therefore, we consider that marine yeasts could be shifted by the Kuroshio Current and drift in aerosols with sea wind.

As previously described, yeasts were also frequently isolated from marine organisms (Kawakita \& van Uden 1965, Fell 1967, Buck et al. 1977, Kutty \& Philip 2008). Marine organisms are therefore suggested as another mechanism for controlling the distribution of yeasts. However, more evidence is needed to support this hypothesis.

In conclusion, our results provide information on the distribution and taxonomy of marine yeasts in the coastal waters of northeastern Taiwan. The results indicate that Candida tropicalis was the most frequently recovered yeast collected from the sampling stations. Future work will focus on investigating characteristics of these isolates, such as salt tolerance, alcohol production ability and carbohydrate fermentation, and their applications to food fermentation and other industries.

Acknowledgements. We thank R. E. Wu, J. J. Jeng, W. M. Li, and P. S. Lin for their technical assistance during the sampling and isolation.

\section{LITERATURE CITED}

Bhadra B, Sreenivas Rao R, Naveen Kumar N, Chaturvedi P, Sarkar PK, Shivaji S (2007) Pichia cecembensis sp. nov. isolated from a papaya fruit (Carica papaya L., Caricaceae). FEMS Yeast Res 7:579-584

Buck JD, Bubucis PM, Combs TJ (1977) Occurrence of human-associated yeasts in bivalve shellfish from Long Island Sound. Appl Environ Microbiol 33:370-378

Cheng YC, Lin LP (1977) Microbiological studies on western coast of Taiwan. I: Enumeration, isolation and identification of marine-occurring yeasts. Acta Oceanogr Taiwan 7:216-228

Fell JW (1967) Distribution of yeasts in the Indian Ocean. Bull Mar Sci 17:454-470

- Hill J, Nelson E, Tilman D, Polasky S, Tiffany D (2006) Environmental, economic, and energetic costs and benefits of biodiesel and ethanol biofuels. Proc Natl Acad Sci USA 103:11206-11210

Kawakita S, van Uden N (1965) Occurrence and population densities of yeast species in the digestive tracts of gulls and terns. J Gen Microbiol 39:125-129

Kodama K (1999) Isolation of Saccharomyces cerevisiae from the marine environment and their applications. J Brew Soc Jpn 94:879-883

Kutty SN, Philip R (2008) Marine yeasts - a review. Yeast 25:465-483

Lee CF, Liu CH, Young SS, Chang KS (2008) Kazachstania jiainicus sp. nov., an ascomycetous yeast species isolated from soil in Taiwan. FEMS Yeast Res 8:114-118
Liu KK, Tang TY, Gong GC, Chen LY, Shiah FK (2000) Crossshelf and along-shelf nutrient fluxes derived from flow fields and chemical hydrography observed in the southern East China Sea off northern Taiwan. Cont Shelf Res 20: 493-523

Liu CH, Young SS, Chang TC, Lee CF (2008) Candida dajiaensis sp. nov., Candida yuanshanicus sp. nov., Candida jianshihensis sp. nov., and Candida sanyiensis sp. nov., four anamorphic, ascomycetous yeast species isolated from soil in Taiwan. FEMS Yeast Res 8:815-822

- Matsushika A, Watanabe S, Kodaki T, Makino K, Sawayama S (2008) Bioethanol production from xylose by recombinant Saccharomyces cerevisiae expressing xylose reductase, NADP(+)-dependent xylitol dehydrogenase, and xylulokinase. J Biosci Bioeng 105:296-299

- Mikata K, Ueda-Nishimura K, Hisatomi T (2001) Three new species of Saccharomyces sensu lato van der Walt from Yaku Island in Japan: Saccharomyces naganishii sp. nov., Saccharomyces humaticus sp. nov. and Saccharomyces yakushimaensis sp. nov. Int J Syst Evol Microbiol 51: 2189-2198

Nisiotou AA, Gibson GR (2005) Isolation of culturable yeasts from market wines and evaluation of the 5.8S-ITS rDNA sequence analysis for identification purposes. Lett Appl Microbiol 41:454-463

> Noda M, Ikeda I, Ueno S, Hashimoto H, Gushima K (1998) Enrichment of coastal zooplankton communities by drifting zooplankton patches from the Kuroshio front. Mar Ecol Prog Ser 170:55-65

Nyanga LK, Nout MJ, Gadaga TH, Theelen B, Boekhout T, Zwietering $\mathrm{MH}$ (2007) Yeasts and lactic acid bacteria microbiota from masau (Ziziphus mauritiana) fruits and their fermented fruit pulp in Zimbabwe. Int J Food Microbiol 120:159-166

> Osorio-Cadavid E, Chaves-López C, Tofalo R, Paparella A, Suzzi G (2008) Detection and identification of wild yeasts in Champús, a fermented Colombian maize beverage. Food Microbiol 25:771-777

Passoth V, Schnürer J (2003) Non-conventional yeasts in antifungal application. In: de Winde JH (ed) Functional genetics of industrial yeast. Springer Verlag, Berlin, p 297-319

Rao RS, Bhadra B, Shivaji S (2008) Isolation and characterization of ethanol-producing yeasts from fruits and tree barks. Lett Appl Microbiol 47:19-24

Taysi I, van Uden N (1964) Occurrence and population densities of yeast species in an estuarine-marine area. Limnol Oceanogr 9:42-45

Tien CJ, Wang PH (2004) Yeast flora in the Er-Jen River. Taiwan J Agric Chem Food Sci 42:36-42

van Uden N, Branco RC (1963) Distribution and population densities of yeast species in Pacific water, air, animals, and kelp off southern California. Limnol Oceanogr 8:323-329

> Vogel C, Rogerson A, Schatz S, Laubach H, Tallman A, Fell J (2007) Prevalence of yeasts in beach sand at three bathing beaches in South Florida. Water Res 41:1915-1920

Wang L, Chi Z, Wang X, Ju L, Chi Z, Guo N (2008) Isolation and characterization of Candida membranifaciens subsp. flavinogenie W14-3, a novel riboflavin-producing marine yeast. Microbiol Res 163:255-266

Yamagata K, Fujita T (1970) Studies on yeasts isolated from sake-cake pickle and soya-mash: (I) Identification and salt-tolerance of yeasts. Ferment Technol 48:485-492

Yanagida F, Kodama K, Shinohara T (2002) Selection of marine yeast stock for making white wine. J Brew Soc Jpn 97:150-161

Submitted: July 27, 2009; Accepted: November 3, 2009

Proofs received from author(s): December 19, 2009 